\section{Endoscopic resection of nasopharyngeal angiofibroma: the role of radio-frequency coblation}

\author{
Rohana Ali, Ivan Keogh, John Lang \\ Department of Otorhinolaryngology, \\ University College Hospital Galway and \\ Academic Department of \\ Otorhinolaryngology, National University \\ of Ireland, Galway, Republic of Ireland
}

\section{Abstract}

Nasopharyngeal angiofibromas are histologically benign but locally aggressive vascular tumors that can result in major morbidity and mortality. They exclusively affect adolescent male and are rare in patients older than 25 years. The management of nasopharyngeal angiofibroma is primarily surgical. Most small and medium sized tumors are resected endoscopically with a microdebrider. Our presentation demonstrates the role of radio-frequency coblation in the endoscopic management of angiofibroma that is confined to the nasal cavity, nasopharynx and paranasal sinuses. Through a brief video presentation, viewers will be able to appreciate the role of this instrument. We reviewed the case of an adult male patient who presented to our institute with nasopharyngeal angiofibroma. He underwent pre-operative embolization followed by endoscopic coblation of the tumor. A video demonstration is presented of a patient with nasopharyngeal angiofibroma who underwent successful transnasal endoscopic coblation. The coblator was used to resect the tumour attachment at the posterior end of the middle turbinate and the nasopharynx. The tumor was resected en-bloc and pushed into the oropharynx and eventually removed trans-orally. The natural ostium of the sphenoid sinus was enlarged and the residual tumor was removed. Absorbable nasal packing was inserted for haemostasis. Intra-operative bleeding was negligible. Radio-frequency coblation has a definite role in the endoscopic resection of small and medium sized nasopharyngeal angiofibroma. This technique is easy to learn and is extremely efficient. Tumors can be removed with minimal or no damage to surrounding tissues and intra-operative bleeding is negligible.

\section{Introduction}

Nasopharyngeal angiofibroma is a benign neoplasm composed of an admixture of mature vascular and fibrous tissue, with locally destructive properties. This tumor is very rare and accounts for $0.05 \%$ of all head and neck tumours. ${ }^{1}$ It occurs almost exclusively in males, commonly in second decade of life. The incidence in other age group and female population is exceptional.

Nasopharyngeal angiofibroma typically originates from a fibrovascular nidus in the posterolateral nasal cavity wall near the superior margin of the sphenopalatine foramen. It can grow inferiorly down into the nasopharynx and postnasal space or progress posteriorly and erode through the anterior space of the sphenoid sinus and back and through and disrupt the roots of the pterygoid plates. It can expand and become continuous with the inferior or middle turbinate or push forward into the posterior wall of the maxillary sinus (the anterior bowing of the maxillary antrum is considered to be pathognomonic for angiofibroma also known as Holman Miller sign). It can also grow laterally into the pterygopalatine fossa or the infratemporal fossa or even through the orbital fissures and dura of the middle cranial fossa.

Pre-operative embolization of the feeding vessel of the tumor has been shown to significantly decrease intra-operative bleeding significantly. ${ }^{2}$ Effective pre-embolization is important in endoscopic surgery so that that surgery on the tumor does not result in the surgical field being obscured by excessive bleeding. Excessive bleeding can often result in incomplete removal of the tumor with a high risk of recurrence.

The management of nasopharyngeal angiofibroma is primarily surgical. Most small and medium size nasopharyngeal angiofibroma are resected endoscopically with a microdebrider. Previous experience in our institute has shown that microdebrider caused a lot of intra-operative bleeding even after successful embolization. We also noted that the firm rubbery tissue of the angiofibromas does not readily enter the jaw of the microdebrider.

Radio-frequency coblation has been increasingly used throughout otorhinolaryngology. Tissues are removed by vaporization, achieved through the production of an ionized plasma vapor. The depth of vaporization is very limited and is achieved with virtually no heat production, resulting in minimal thermal damage to adjacent tissue.

It has been shown to provide impressive benefit as a technique for adenotonsillectomy and uvulopalatoplasty by reducing pain and early return to diet..$^{3-5}$ Charring and tissue distortion caused by coblation is very minimal and this technique has shown to cause statistically significant lower estimated blood loss and blood loss per minute when used for endoscopic polypectomy compared with the traditional micro debridement technique. ${ }^{6}$
Correspondence: Rohana Ali, Apt 1. An Coirneal, Pier Road, Barna Co., Galway, Ireland.

Tel. +353.91.542000 - Fax: 0035391526637.

E-mail: rohana.oconnell@gmail.com

Key words: radio-frequency coblation, nasopharyngeal angiofibroma, endoscopic resection.

Conflict of interest: the authors report no conflicts of interest.

Received for publication: 18 June 2011. Revision received: 7 August 2011.

Accepted for publication: 29 August 2011.

This work is licensed under a Creative Commons Attribution NonCommercial 3.0 License (CC BYNC 3.0).

(C) Copyright R. Ali et al., 2011

Licensee PAGEPress, Italy

Surgical Techniques Development 2011; 1:e13 doi:10.4081/std.2011.e13

In our institute, coblator-assisted endoscopic resection of vascular tumor had been performed on 2 patients. Tumors were confined to the nasal cavity, nasopharynx and paranasal sinus, with no evidence of intracranial extension. Both patients underwent successful preoperative embolization followed by coblatorassisted endoscopic resection of the tumor. A representative case report as well as video clip of the operation is presented (Video 1).

\section{Case Report}

A 50-year-old male presented to our department with a 4 months history of unilateral left nasal obstruction. Initial endoscopic examination with a 0 degree scope revealed a polypoidal red mass originating from the posterior end of middle turbinate extending and filling up the nasopharynx. The mass was fibrotic and there was no evidence of bleeding at that time.

A contrast enhanced computed tomography (CT) scan (Figure 1) and magnetic resonance imaging (MRI) (Figure 2) demonstrated a mass originating from the left middle turbinate extending into the nasopharynx and left sphenoid sinus. There was no intracranial extension. The mass in the nasopharynx measured approximately $40 \times 30 \times 23 \mathrm{~mm}$ while the extension into the left sphenoid sinus measured approximately $20 \times 17 \times 8 \mathrm{~mm}$.

Biopsy of this mass was taken under general anesthesia. A single punch biopsy caused profuse bleeding. Histology revealed the vascular network of angiofibroma (Figure 3). The network composed of thin walled blood vessels that vary in appearance from stellate to 
staghorn to inconspicuous. There is marked compression of vascular components by stromal fibrous tissue. Based on the histological findings, patient underwent embolization of the feeding vessel, in this case the left internal maxillary artery.

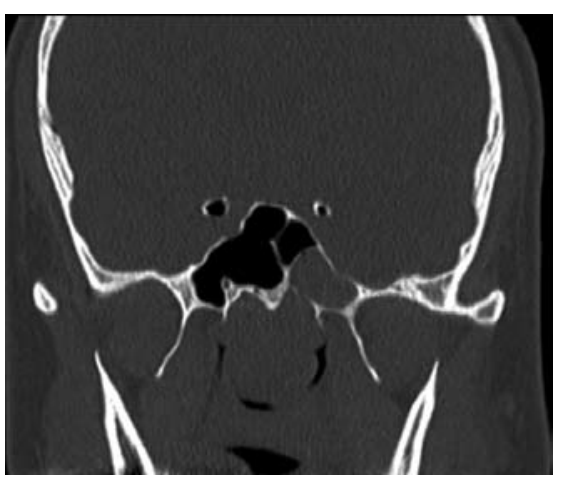

Figure 1. Contrast enhanced computed tomography scan showing the coronal section of nose and sphenoid sinus. Tumor is extending from the nose into the nasopharynx and left sphenoid sinus.

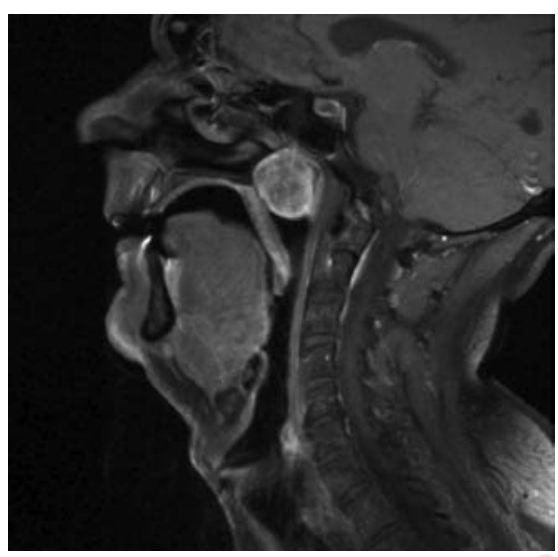

Figure 2. Magnetic resonance imaging showing sagittal section of the tumor filling the nasopharynx.

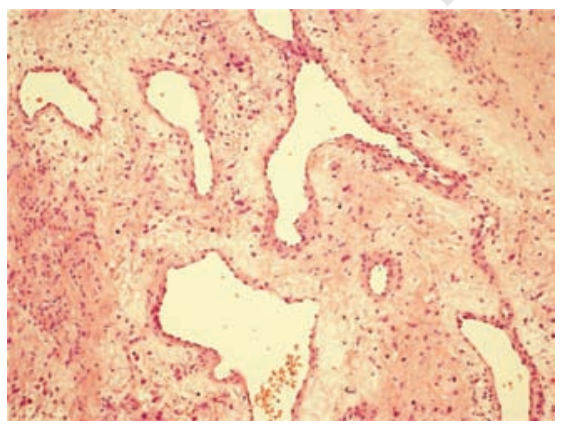

Figure 3. Histology shows the vascular network of angiofibroma. The network is composed of thin walled blood vessels that vary in appearance from stellate to staghorn to inconspicuous. There is marked compression of vascular components by stromal fibrous tissue.

\section{Technique}

Patient was positioned in a reverse trendelenburg position and intubated via endotracheal anesthesia. The patient's nose was sprayed with lignocaine and phenylephrine hydrochloride (co-phenylcaine forte) followed by cotton pledgets soaked with $1 \%$ adrenaline. The 0 degree scope was inserted into the left nasal cavity and the middle turbinate was medialized using a Cottle elevator. The polypoidal red mass became readily visible as a continuation of the posterior end of the middle turbinate.

Coblation probes were sourced from ArthroCare ENT Limited. EVac ${ }^{\circledR}$ Coblator probe carries three separate actions: suction and ablation for volumetric tissue removal, coagulation for tissue shrinkage and haemostasis. The continuous presence of saline irrigation helps to limit the amount of heat delivered to the surrounding structure and hence reduce the amount of post operative pain experienced by the patient. The probe was set for coblation (setting 5) and coagulation (setting 3).

Starting from the anterior attachment of the tumor, the coblator wand was used to resect the tumor into the nasopharynx. The posterior attachments of the tumor were coblated and mobilized inferiorly. Once all attachments were taken down, delivery of the tumor was initiated. Because of the large size of the tumor, it could not be delivered trans-nasally; rather it was pushed down into the oropharynx and delivered through the mouth. The first specimen measured about 30 to $40 \mathrm{~mm}$. The natural ostium of the sphenoid sinus was enlarged and, once adequately exposed; a grasping forceps was used to remove the second half of the tumour which measured about 15 to $20 \mathrm{~mm}$. After the tumor was removed, the nasal cavity and sphenoid sinus were inspected. Adrenaline pledgets were instilled again into both nasal cavity and then the nose was packed with Rapid Rhino ${ }^{\circledR}$ (absorbable nasal pack) that was moistened with sterile water. The patient was extubated and had an uneventful recovery. Estimated blood loss was approximately $25 \mathrm{~mL}$. Patient was discharged the following day. He was seen again in the outpatient clinic 2 weeks later and had no postoperative complications.

\section{Discussion}

The techniques for removal of nasopharyngeal angiofibroma have evolved from open approaches such as lateral rhinotomy and midface gloving to endoscopic removal using a microdebrider. Radiofrequency coblation is now well known throughout otorhinolaryngology and this tool has shown to provide impressive benefit as a technique for adenotonsillec- tomy, reducing post-operative pain and allowing early return to normal diet and daily activities. Belloso et al. has also shown that pain and complications following coblation palatoplasty are significantly less when compared to laser technique. ${ }^{7}$

Radiofrequency coblation uses a controlled, non-heat driven process in which bipolar radiofrequency excites the electrodes in a conductive medium such as saline solution, creating a precisely focused and charged plasma gas. The energized particles in the plasma have sufficient energy to break the molecular bonds within tissue, causing tissue to dissolve at relatively low temperatures typically between $40^{\circ} \mathrm{C}$ to $70^{\circ} \mathrm{C}$. The radiofrequency current does not pass directly through the tissue during the coblation process, thus tissue heating is minimal. The result is volumetric removal of the target tissue with minimal damage to surrounding healthy tissue

Currently coblation is increasingly being used in head and neck surgery and endoscopically assisted procedures. ${ }^{3,8}$ Again desirable results such as limited damage to underlying tissue and bloodless field were achieved.

Endoscopic-assisted radiofrequency coblation of nasopharyngeal angiofibroma has given us promising results especially in resecting tumor that is confined to the nasal cavity, nasopharynx and paranasal sinus. We believe this presentation justifies further evaluation of this interesting technique in resection of nasopharyngeal angiofibroma.

\section{References}

1. Herman P, Lot G, Chapot R, et al. Long term follow-up of juvenile nasopharyngeal angiofibromas: analysis of recurrences. Laryngoscope 1999;109:140-7.

2. Moulin G, Chagnaud C, Gras R, et al. Juvenile nasopharyngeal angiofibroma: comparison of blood loss during removal in embolized group versus nonembolized group. Cardiovasc Intervent Radiol 1995; 18:158-61.

3. Patel J, Mandal S, Rachmanidou A. Paediatric coblation tonsillectomy versus dissection tonsillectomy: a comparative study of post-operative pain and complications. Int $\mathrm{J}$ Pediatr Otorhinolaryngol 2004;68:725.

4. Parsons SP, Cordes SR, Comer, B. Comparison of posttonsillectomy pain using the ultrasonic scalpel, coblator, and electrocautery. Otolaryngol Head Neck Surg 2006;134:106-13.

5. Rombaux P, Hamoir M, Bertrand B, et al. Postoperative pain and side effects after uvulopalatopharyngoplasty, laser-assisted uvulopalatoplasty, and radiofrequency tis- 
sue volume reduction in primary snoring. Laryngoscope 2003;113:2169-73.

6. Eloy JA, Walker TJ, Casiano RR, Ruiz JW. Effect of coblation polypectomy on estimated blood loss in endoscopic sinus surgery.
Am J Rhinol Allergy 2009;23:535-9.

7. Belloso A, Chidambaram A, Morar P, Timms MS. Coblation tonsillectomy versus dissection tonsillectomy: postoperative hemorrhage. Laryngoscope 2003;113:2010-
3.

8. Carney S, Psaltis A. Radiofrequency coblation for the treatment of laryngotracheal papillomas. Otolaryngol Head Neck Surg 2004;131:137. 